\title{
Effect of Sexual Educational Package on Knowledge and Female Sexual Function for Pregnant Women
}

\author{
Doaa Mohamed Sobhy Elsayed ${ }^{1}$, Amira Refaat Said ${ }^{2,}$, , Ola Abdel-Wahab Afifi Araby ${ }^{2}$ \\ ${ }^{1}$ Community Health Nursing, Faculty of Nursing, Benha University, Benha, Egypt \\ ${ }^{2}$ Obstetrics and Woman's Health Nursing, Faculty of Nursing, Benha University, Benha, Egypt
}

Email address:

Amira.refaat21@yahoo.com (A. R. Said)

${ }^{*}$ Corresponding author

\section{To cite this article:}

Doaa Mohamed Sobhy Elsayed, Amira Refaat Said, Ola Abdel-Wahab Afifi Araby. Effect of Sexual Educational Package on Knowledge and Female Sexual Function for pregnant Women. American Journal of Nursing Science. Vol. 8, No. 5, 2019, pp. $210-222$.

doi: 10.11648/j.ajns.20190805.12

Received: June 8, 2019; Accepted: June 29, 2019; Published: August 5, 2019

\begin{abstract}
Background: Sexual activity is a mutual relationship and any change in women's sexual function may result in an increase in sexual disorders among the couples. Many previous studies have suggested that sexual education during pregnancy can improve the sexual function of the pregnant women. Aim: of this study was to evaluate effect of the sexual educational package on knowledge and female sexual function for pregnant women. Design: Quasi- experimental design was utilized. Sample: A purposive sample of (a total of 100 primigravida, control group $(\mathrm{n}=50)$ and study group $(\mathrm{n}=50)$ who attended antenatal clinic during six months. Setting: The study was carried out in the antenatal clinic at Benha University Hospital. Tools: Data were collected through two main tools: A structured self-administered questionnaire to assess demographic data, personal characteristics and knowledge of the studied sample regarding sexuality and sexual function during pregnancy, and Modified Female Sexual Function Index to assess sexual function in primigravida. Results: showed that the mean age of study and control groups were $23.80 \pm 3.43$ years and $24.18 \pm 1.63$ years respectively. A highly statistical significant difference was observed in knowledge between the two groups after implementing sexual education package $(p<0.001)$. There was a highly significant difference between study and control groups regarding mean FSFI six domains and total scores during the different study phases after implementing sexual educational package $(\mathrm{p}<0.001)$. Conclusion: The sexual educational package had a significant effect on improvement of primigravida pregnant women sexual function and knowledge after implementing sexual educational package. Recommendation: Educational sexual package intervention must be integrated into prenatal consultations and care; establishing strategies to facilitate the women's understanding to discuss sexual disorders freely through applying this study on a large sample in the obstetrics and gynecological outpatient clinics.
\end{abstract}

Keywords: Sexual Education Package, Sexual Function, Pregnancy

\section{Introduction}

The success of a marriage mainly depends on the sexual relationship between the couples and this relation can be seen throughout the life of the youth years to the senescence. So, the Sexual satisfaction and union between couples is important to achieve happiness, pleasure, compassion, love, as well as to a reliable means for satisfaction of sexual desires [1].

Pregnancy is a condition which leads to adverse effect on the quality of the sexual relationship between the couples [2].
These adverse effects occur due to hormonal, emotional changes during pregnancy, which may affect the expression of sexual desires and sexual behavior [3]. Safe sexual function during pregnancy is one of the keystones for couples to go forward from partners to parents [4].

The indices of sexual function are affected during pregnancy with a significant decline in the last trimester [5]. The sexual intercourse frequency is low during pregnancy and reaches lower levels in the third trimester for woman [6]. Additionally, the prevalence of sexual dysfunction during pregnancy has been reported to be $46.6 \%$ in the first trimester, $34.4 \%$ in the second trimester and $73.3 \%$ in the 
third trimester [7].

Most sexual dysfunctions that occur during pregnancy are resulted by a lack of an adequate and proper understanding of the physical and emotional changes at this time. This occur because couples are not provided with information about how they can manage their sexual life during pregnancy since midwives, nurses and obstetricians routinely do not conduct sexual health education [8].

Many studies found that women had a reduction in their sexual function after knowing about their pregnancy. As sexual relationship is a reciprocal relationship, a change in women's sexual function can affect the fulfillment of men's sexual needs and lead to a disturbance in women's sexual function as well as the incidence or increase of sexual disturbance among the couples, which can result in notable discrepancies in couples' marital relationship [9].

The most common causes of sexual dysfunction were physical problems (e.g., backache, pain during intercourse, dyspnea, and weight gain) and false beliefs about intercourse during pregnancy. These misbeliefs include injury to the fetus, fear of increasing the risk of abortion or infection, premature delivery, or lack of attractiveness for the spouse [4].

Therefore, the importance of sex education and counseling during pregnancy has always been proposed. Sexual knowledge may decrease women's anxiety by improving the quality of sexual relationship during pregnancy and decrease the occurrence of sexual problems [10]. Increasingly, women should be educated that in the case of physiological pregnancy, there is no limitation on the sex activity, unless high risk pregnancy has been diagnosed [7].

\subsection{Significance of the Research}

Significant biological, psychological, and physical changes during pregnancy can affect sexual performance of women [11]. Hormonal changes during pregnancy cause vomiting, diarrhea, breast sensitivity, and fatigue, leading to decreased sexual desire. Moreover, the sexual function of the women during pregnancy is affected by their value systems, traditional, religious beliefs, fear of hurting the fetus and mother [12].

It is noteworthy that more than half of the women didn't receive information about sexual intercourse during pregnancy. This could be either due to not asking about sexual coition during pregnancy on the part of the women or the negligence of the healthcare providers. Additionally, the lack of appropriate interaction between the women and health care providers leads to receiving inadequate information related to sexual function, which is a critical issue in communities [13]. Therefore, the present study aims to highlight effect of sexual educational package on knowledge and female sexual function for pregnant women.

\subsection{Aim of the Research}

The aim of the current study was to evaluate effect of sexual educational package on knowledge and female sexual function for pregnant women.

\subsection{Research Hypotheses}

To achieve the aim of this research, the following research hypotheses were formulated:

H1. Pregnant women, who will receive the sexual educational package, will have a better knowledge after implementing sexual educational package than those who don't.

H2. Pregnant women with sexual dysfunction, who will receive the sexual educational package, will show higher sexual function scores after implementing sexual educational package than those who don't.

\section{Subjects and Method}

\subsection{Research Design}

A quasi-experimental design was utilized to achieve the aim of the present research.

\subsection{Setting}

The present research is carried out among primigravida women in the antenatal clinic at Benha University Hospital. This hospital located in Benha City at Qalioubia Governorate. This particular setting was chosen because it is main hospital providing care for women with different social backgrounds and high risk women. Also it's a clinical training setting for nursing students in the Faculty of Nursing. This hospital started to provide care since its opening in 1981; it provides free and economical service to all patients. The hospital receives large numbers of women each month who seek care for follow up during pregnancy from different areas (urban \& rural area). Almost the hospital receives about 500 primigravida women annually who seek care during pregnancy (from official records) [14].

\subsection{Sampling}

\subsubsection{Sample Type and Criteria}

A Purposive sample of primigravida women attending antenatal clinic during six months were recruited for the study according to the following inclusion criteria: Primigravida, being in the 10-12th week of pregnancy living permanently with a spouse, can read \& write, no past or present history of medical disorder, no smoking and lack of coitus for any medical problem, free from any obstetrics related disorders, and who had telephone number for contact and all women who accepted to participate in the study.

\subsubsection{Sample Size and Technique}

Data were collected for a period of six months (100 primigravida) after exclusion of primigravida who didn't fulfill inclusion criteria. In order to avoid bias through data collection, the primigravida women admitted to antenatal clinic during first three months and attaining selection criteria from beginning of data collection were recruited at the control group $(\mathrm{n}=50)$, and other primigravida women with same criteria, who admitted during the second three months of data collection were recruited at the study group $(n=50)$. 


\subsection{Tools for Data Collection}

Two tools were constructed to collect the necessary data about the study subjects as following:

\subsubsection{Tool I: A structured Self-administered Questionnaire}

It was designed by the researchers after reviewing related literature it was written in simple Arabic language. It encompassed three main parts:

Part 1: Personal characteristics of the studied sample. This part consisted of (9) items and was concerned with data related to pregnant women's age, educational level, residence, income, occupation, type of family, husband's educational level and occupation.

Part 2: Obstetric and sexual history of the studied sample. This part included (7) questions related to gestational age in weeks, frequency of sexual intercourse, suffering from any sexual problems before pregnancy, presence of sexual problems during the current pregnancy, age of marriage, duration of marriage, receiving any information about sexual relations before.

Part 3: Women's knowledge regarding sexuality and sexual function during pregnancy. This part was utilized before and after applying the sexual educational package (pre/posttest format), It consisted of (12) open ended questions related to the components of the female reproductive system, the most erotic places for woman $\&$ men, information about the stages of sexual response, effects of pregnancy on the stages of sexual response, information on how to overcome the loss of desire during pregnancy, safety of sexual intercourse on the

\section{Scoring system}

Total score for every domain:

$\begin{array}{ll}\text { Domains of sexual function } & \text { Questions } \\ \text { Desire } & 1,2 \\ \text { Arousal } & 3,4,5,6 \\ \text { Lubrication } & 7,8,9,10 \\ \text { Orgasm } & 11,12,13 \\ \text { Satisfaction } & 14,15,16 \\ \text { Pain } & 17,18,19\end{array}$

Full Scale Score Range

\subsubsection{Ethical Considerations}

Ethical approval was obtained from the research ethical committee of the Faculty of Nursing, Benha University. Then official permission was granted from director of Benha University Hospital, to facilitate data collection process. The researchers explained the aim of the study to the mothers and informed them that the information obtained will be confidential, their participation was in a voluntary base and they have the rights to refuse and/or withdraw at any time without providing a reason. A written Informed consent was taken from women to obtain their acceptance to participate in the research. After the study was completed, the sexual educational package was distributed to control group.

\subsubsection{Validity and Reliability}

The tools were thoroughly reviewed by five experts, two in fetus during pregnancy, the indications in which sexual relation should be avoided during pregnancy, information about the positions of intercourse during pregnancy, the most safe intercourse positions during pregnancy and also the positions should be forbidden intercourse during pregnancy).

Scoring system:

The correct answers were predetermined according to the literature. Each item was assigned a score of (2) was given to the correct and complete answer, a score of (1) was given for correct but incomplete answer and a score of (0) was given for the wrong or no answer. In addition, women's total knowledge scores were converted into total percent and graded as the following three levels: Good ( $\geq 75 \%$ ), average $(50-<75 \%)$, Poor $(<50 \%)$.

\subsubsection{Tool II: Modified Female Sexual Function Index (FSFI) [15]}

The Female Sexual Function Index (FSFI), a 19-item questionnaire, has been slightly modified by the researchers for its scoring system. FSFI has been developed as a brief, multidimensional self-report instrument for assessing the key dimensions of sexual function in women. It provides scores on six domains of sexual function (desire, arousal, lubrication, orgasm, satisfaction, and pain) as well as a total score. The FSFI has been validated on clinically diagnosed samples of women with female sexual arousal disorder (FSAD), female orgasmic disorder (FOD), and hypoactive sexual desire disorder (HSDD). This part was utilized before and after applying the sexual education package (pre/posttest format).

Score Range
$\begin{aligned} & -5 \\ & 0-5 \\ & 0-5 \\ & 0-5 \\ & 0(\text { or } 1)-5 \\ & 0-5\end{aligned}$

Obstetrics \& Woman's health nursing, two in Community Health Nursing and one obstetrician for content validation. As per their opinions, some modifications were required and done in the form of omission, adding and paraphrasing some questions and statements. Reliability of the tools was performed to confirm its consistency. The reliability was done by Cronbach's Alpha coefficient test which revealed that each of the two tools consisted of relatively homogenous items, which it was 0.83 .

\subsubsection{Pilot Study}

A pilot study was carried out on $10 \%$ of total duration of collected data (18 days). It was conducted to test the simplicity, feasibility, clarity and applicability of the developed tools, also to find out the possible obstacles and problems that might face the researchers and interfere with 
data collection, and to estimate the time needed for data collection. According to the results of the pilot study, required modifications were done in the form of adding or omission of some questions and change types of some questions from open ended questions to closed ended questions'. The women involved in the pilot were excluded from the study.

\subsection{Sexual Educational Package Construction}

Upon obtaining official permission from director of Benha University Hospital, data were collected through five phases. The following phases were adopted to fulfill the aim of the current research; preparatory, assessment, planning, implementation, and evaluation phases. These phases were carried out from the beginning of December 2018 to the end of May 2019 covering six months.

\subsubsection{Preparatory Phase}

The preparatory phase was the first phase of the research, the researchers carried out through review of local and international related literature about the various aspects of the research problem. This helped the researchers to be acquainted with magnitude and seriousness of the problem, and guided the researchers to prepare the required data collection tools. Tools were distributed to five experts in the field, these included two maternity nursing professors and one obstetrician, the aim was to test its appropriateness, comprehensiveness, clarity, importance and applicability. The jury recommended omissions of some items or addition which were done; the items on which $95 \%$ or more of the experts have agreed were included in proposed tool. During this phase an official approval to conduct the research was obtained by submission an official letter issued from the Dean of Faculty of Nursing at Benha University to the director of Benha University Hospital in order to obtain their agreement to conduct the research after explaining its purpose and get the statistical numbers of primigravida women enrolled within hospital annually.

\subsubsection{Assessment Phase}

This phase encompassed interviewing the pregnant women in the waiting room of the antenatal clinic (in both study and control group) to collect baseline data, at the beginning of interview the researchers greeted each woman, explained the purpose, duration, and activities of the study. Pre-test was done to assess women's' knowledge and female sexual function index. The data obtained during this phase constituted the baseline for further comparison to evaluate the effect of a sexual educational package. Average time for the completion of each women self-administered questionnaire was around (25-35minutes). The control group was assessed first to avoid cross contamination of information between both groups.

\subsubsection{Planning Phase}

Based on baseline data obtained from assessment phase and relevant review of literature, the educational intervention was developed by the researchers in a form of printed Arabic booklet to satisfy the studied pregnant women's deficit knowledge regarding sexual function during pregnancy and to improve their sexual function index. The general objective of the sexual educational package was to acquire essential knowledge needed to improve women's knowledge and their sexual function index..

\subsubsection{Implementation Phase}

Implementation of an educational intervention took (24) weeks period. The researchers visited the previous mentioned setting two days/week (Tuesday and Wednesday) from 9.00 Am to $12.00 \mathrm{Pm}$. The educational intervention involved (2) scheduled sessions, once a week for two consecutive weeks. These sessions were repeated to each subgroup of (2-3) women in the study group. It was conducted in the waiting room of the antenatal outpatient clinic immediately after completion of the assessment phase. The duration of each session lasted from 50 minutes to one hour including periods of discussion according to their achievement, progress and feedback. Also at the beginning of the first session an orientation to the educational intervention and general objective was explained. Arabic language was used to suit the women's level of understanding. Feedback was given in the beginning of each session about the previous one. Different methods of teaching were used such as modified lecture, group discussion and brainstorming. Suitable teaching media were included an educational booklet that distributed to all women in the first day of the educational intervention as well as audio-visual aids were used (power points (including figures) and the genital models). In the first session, the topics including genital anatomy and sexual physiology consisting of orientation with erotic organs, sexual responses cycle, and the impact of pregnancy on sexual response cycle were discussed. In the second session, the topics including the effect of pregnancy on sexual behavior, sexual intercourse techniques, safe position during pregnancy, sexual skills, and common concerns related to sex such as the risk of miscarriage and PROM as a result of coitus during pregnancy were taught. At the end of the first session, the written educational booklet was handed out to the pregnant women. The researchers explained to the pregnant women how to use the package throughout setting directions including;

1. Carefully read each chapter, and avoid cancel any page in the package.

2. Studying the contents together with their spouses.

3. Pregnant women can return to the researchers in order to clarify the vague points and answer any questions via e-mail, telephone numbers and in the second sessions.

4. Asking their probable questions in the next session and the educator contact number was given to them in order to answer their questions.

\subsubsection{Follow up and Evaluation Phase}

For study group, the sexual educational intervention was evaluated by using the same format of tools which used before intervention to evaluate pregnant women's knowledge 
regarding sexual function during pregnancy. Follow up and evaluation of female sexual function index questionnaire (tool II) were scheduled (3) times, four weeks after education (14-16 weeks), at the end of the second trimester (26-28 weeks) and at the end of the third trimester (34-36 weeks).

For control group the studied women of control group received routine prenatal care, didn't receive sexual education by the researcher and were followed as the same in the study group.

\subsubsection{Statistical Analysis}

Data were verified prior to computerized entry. The Statistical Package for Social Sciences (SPSS version 20.0) was used. Descriptive statistics were included frequencies and percentages for qualitative variables, also means and standard deviations for quantitative variables. Test of significance (chi square, independent $t$ test, $F$-test and paired t test) was applied to test the study hypothesis. A statistically significant difference was considered at $p$-value $p \leq 0.05$, a highly statistically significant difference was considered at $\mathrm{p}$ value $\mathrm{p} \leq 0.001$, and non-significant difference obtained at $\mathrm{P}>0.05$. (Pearson $\mathrm{r}$ ) correlation coefficient used to test the association between variables

\subsubsection{Limitations}

Sometimes, the waiting room of the antenatal clinic may be crowded and noisy. So, the researchers may wait long times until the room become quiet and empty to start the educational sessions. The sexual educational sessions need to be in more private and suitable place to help the pregnant women feeling free during educational sessions.

\section{Results}

Table 1 shows personal characteristics of the studied sample. It was cleared that $58.0 \% \& 66.0 \%$ of both study and control groups respectively were aged $<25$ years with a mean age of $23.80 \pm 3.43$ years and $24.18 \pm 1.63$ years respectively. As regards the residence, $56.0 \%$ of the study group and $70.0 \%$ of control group were lived in rural area. Furthermore, educational level of $36.0 \% \& 26.0 \%$ of both study and control groups respectively were middle education. The husband's educational level of both study and control groups were university education by percentage of $(32.0 \%$ and $24.0 \%)$ respectively. Regarding the employment, more than two thirds (72.0 and 66.0) of both study and control groups respectively weren't work. But in relation to husband's job, $(62.0 \%$ and $68.0 \%)$ of both the study and control groups respectively were employee. As far as monthly income, about half of both the study and control groups $(52.0 \%$ and $48.0 \%$ respectively) had insufficient income. Increasingly, $(52.0 \%$ and $54.0 \%)$ of both study and control groups respectively lived with nucleus family. No statistically difference was detected among both groups related to personal characteristics, which mean that the two groups under study are homogenous.
Table 2 illustrates that, the gestational age of $44 \%$ of study and $36 \%$ of control groups were 12 weeks. Regarding

frequency of sexual intercourse, $42 \%$ of study and $48 \%$ of control groups were 2-4 / month. Furthermore, more than three quarters of both study and control groups didn't receive any information about sexual relations before. Also, $(96.0 \%$ and $90.0 \%$ ) of both study and control groups respectively didn't suffer from any sexual problems before pregnancy. Moreover, (86.0\% and $84.0 \%$ ) of both study and control groups complained from presence of sexual problems during the current pregnancy. No statistically difference was detected between both groups related to obstetric and sexual history, which mean that the two groups under study are homogenous.

Table 3 indicates that, the mean age at marriage was 21.56 \pm 2.80 and $22.34 \pm 2.13$ years of both study and control groups respectively. The mean of marriage duration for both study and control groups was $(1.80 \pm 1.10$ and $1.36 \pm .59$ years respectively), which means that there was statistically difference between both groups.

Table 4 indicates that, there is no statistically significant difference was found in knowledge between both study and control groups before sexual educational package implementation related to knowledge about sexual function during pregnancy. Meanwhile, a highly statistically significant difference was observed in knowledge between two groups after implementing sexual education package at p-values $<0.001$.

Figure 1 displays that, only $12.0 \%$ of study group and $18.0 \%$ of control group had good knowledge before implementation of sexual education package regarding sexual intercourse during pregnancy. Meanwhile, after implementation of sexual education package, $86.0 \%$ of study group had good knowledge compared with $28.0 \% \%$ of the control group.

Table 5 shows that repeated measures for comparing mean FSFI six domains and total scores during the study period in the two groups. These results show a highly significant difference between study and control groups regarding mean FSFI six domains and total scores during the different study phases after implementing sexual educational package at $\mathrm{p}$ values $<0.001$.

Figure 2 demonstrates that the highest mean scores of FSFI was observed in the time of (26-28 weeks- second trimester) after intervention for study group, while the minimum mean scores of FSFI was related to the time of (10-12 weeks-first trimester) before intervention. Meanwhile, for control group, the highest mean scores of FSFI was observed in the time of 4 weeks after intervention. While the minimum mean scores of FSFI was related to the time of (10-12 weeks-first trimester) before intervention.

Table 6 indicates that, a highly significant correlation was discovered between total scores of FSFI and total knowledge in study group after implementing sexual education package. 
Table 1. Distribution of the studied sample (control and study group) according to their personal characteristics $(n=100)$.

\begin{tabular}{|c|c|c|c|c|c|c|}
\hline \multirow{2}{*}{ Group Personal characteristics } & \multicolumn{2}{|c|}{ Study group $\mathbf{n}=\mathbf{5 0}$} & \multicolumn{2}{|c|}{ Control group $\mathbf{n}=\mathbf{5 0}$} & \multirow{2}{*}{$\mathbf{X} 2$} & \multirow{2}{*}{ p-value } \\
\hline & No & $\%$ & No & $\%$ & & \\
\hline \multicolumn{7}{|l|}{ Age } \\
\hline$<25$ & 29 & 58.0 & 33 & 66.0 & \multirow{4}{*}{0.69} & \multirow{4}{*}{0.70} \\
\hline $25-$ & 12 & 24.0 & 10 & 20.0 & & \\
\hline$\geq 35$ & 9 & 18.0 & 7 & 14.0 & & \\
\hline Mean \pm SD & \multicolumn{2}{|l|}{$23.80 \pm 3.43$} & \multicolumn{2}{|c|}{$24.18 \pm 1.63$} & & \\
\hline \multicolumn{7}{|l|}{ Residence } \\
\hline Rural & 28 & 56.0 & 35 & 70.0 & \multirow{2}{*}{2.10} & \multirow{2}{*}{0.14} \\
\hline Urban & 22 & 44.0 & 15 & 30.0 & & \\
\hline \multicolumn{7}{|l|}{ Education } \\
\hline Read and write & 8 & 16.0 & 10 & 20.0 & \multirow{4}{*}{1.24} & \multirow{4}{*}{0.74} \\
\hline Basic education & 10 & 20.0 & 12 & 24.0 & & \\
\hline Middle education & 18 & 36.0 & 13 & 26.0 & & \\
\hline University education & 14 & 28.0 & 15 & 30.0 & & \\
\hline \multicolumn{7}{|l|}{ Employment } \\
\hline Work & 14 & 28.0 & 17 & 34.0 & \multirow{2}{*}{0.42} & \multirow{2}{*}{0.51} \\
\hline Do not work & 36 & 72.0 & 33 & 66.0 & & \\
\hline \multicolumn{7}{|l|}{ Income } \\
\hline Sufficient & 5 & 10.0 & 9 & 18.0 & \multirow{3}{*}{0.69} & \multirow{3}{*}{0.70} \\
\hline Fairly sufficient & 19 & 38.0 & 17 & 34.0 & & \\
\hline Insufficient & 26 & 52.0 & 24 & 48.0 & & \\
\hline \multicolumn{7}{|l|}{ Family Type } \\
\hline Nucleus family & 26 & 52.0 & 27 & 54.0 & \multirow{2}{*}{0.04} & \multirow{2}{*}{0.84} \\
\hline Extended family & 24 & 48.0 & 23 & 46.0 & & \\
\hline \multicolumn{7}{|l|}{ Husband's educational level } \\
\hline Read and write & 14 & 28.0 & 18 & 36.0 & \multirow{5}{*}{1.47} & \multirow{4}{*}{0.68} \\
\hline Basic education & 10 & 20.0 & 8 & 16.0 & & \\
\hline Middle education & 10 & 20.0 & 12 & 24.0 & & \\
\hline University education & 16 & 32.0 & 12 & 24.0 & & \\
\hline \multicolumn{6}{|l|}{ Husband's job } & \\
\hline Employee & 31 & 62.0 & 34 & 68.0 & 030 & 052 \\
\hline Free business & 19 & 38.0 & 16 & 32.0 & 0.59 & 0.52 \\
\hline
\end{tabular}

Table 2. Distribution of the studied sample (control and study group) according to selected items of their obstetric and sexual history ( $n=100)$.

\begin{tabular}{|c|c|c|c|c|c|c|}
\hline \multirow{2}{*}{$\begin{array}{l}\text { Group Obstetric \& sexual } \\
\text { history }\end{array}$} & \multicolumn{2}{|c|}{ Study group $\mathbf{n = 5 0}$} & \multicolumn{2}{|c|}{ Control group $\mathbf{n}=\mathbf{5 0}$} & \multirow{2}{*}{$\mathrm{X} 2$} & \multirow{2}{*}{ p-value } \\
\hline & No & $\%$ & No & $\%$ & & \\
\hline \multicolumn{7}{|l|}{ Gestational age in weeks } \\
\hline 10 weeks & 15 & 30.0 & 18 & 36.0 & \multirow{3}{*}{0.71} & \multirow{3}{*}{0.70} \\
\hline 11 weeks & 13 & 26.0 & 14 & 28.0 & & \\
\hline 12 weeks & 22 & 44.0 & 18 & 36.0 & & \\
\hline \multicolumn{7}{|c|}{ Frequency of sexual intercourse } \\
\hline Once / month & 16 & 32.0 & 18 & 36.0 & \multirow{4}{*}{1.98} & \multirow{4}{*}{0.57} \\
\hline 2-4 / month & 21 & 42.0 & 24 & 48.0 & & \\
\hline 2-4 / week & 10 & 20.0 & 5 & 10.0 & & \\
\hline More than 4 / week & 3 & 6.0 & 3 & 6.0 & & \\
\hline \multicolumn{7}{|c|}{ Suffering from any sexual problems before pregnancy } \\
\hline No & 48 & 96.0 & 45 & 90.0 & \multirow{2}{*}{1.38} & \multirow{2}{*}{0.24} \\
\hline Yes & 2 & 4.0 & 5 & 10.0 & & \\
\hline \multicolumn{7}{|c|}{ Presence of sexual problems during the current pregnancy } \\
\hline No & 7 & 14.0 & 8 & 16.0 & \multirow{2}{*}{0.07} & \multirow{2}{*}{0.77} \\
\hline Yes & 43 & 86.0 & 42 & 84.0 & & \\
\hline \multicolumn{7}{|c|}{ Receiving any information about sexual relations before } \\
\hline No & 40 & 80.0 & 38 & 76.0 & \multirow{2}{*}{0.23} & \multirow{2}{*}{0.62} \\
\hline Yes & 10 & 20.0 & 12 & 24.0 & & \\
\hline
\end{tabular}


Table 3. Mean scores and standard deviation of studied sample (control and study group) regarding selected items of their obstetric and sexual history $(n=100)$.

\begin{tabular}{|c|c|c|c|c|c|c|}
\hline \multirow{2}{*}{$\begin{array}{l}\text { Group Obstetric and sexual } \\
\text { history }\end{array}$} & \multirow{2}{*}{ Minimum } & \multirow{2}{*}{ Maximum } & \multirow{2}{*}{$\begin{array}{l}\text { Study group } \mathbf{n}=\mathbf{5 0} \\
\text { Mean } \pm \text { SD }\end{array}$} & \multirow{2}{*}{$\begin{array}{l}\text { Control group } \mathbf{n}=50 \\
\text { Mean } \pm \text { SD }\end{array}$} & \multirow{2}{*}{ t-test } & \multirow{2}{*}{ p-value } \\
\hline & & & & & & \\
\hline Age at marriage, $y$ & 17.00 & 32.00 & $21.56 \pm 2.80$ & $22.34 \pm 2.13$ & 1.566 & .120 \\
\hline Marriage duration, $\mathrm{y}$ & 1.00 & 5.00 & $1.80 \pm 1.10$ & $1.36 \pm .59$ & 2.474 & $.015 *$ \\
\hline
\end{tabular}

Independent $\mathrm{t}$ test.

*A statistical significant $\mathrm{p} \leq 0.05$.

$* *$ A highly statistical significant $\mathrm{p} \leq 0.001$.

Table 4. Distribution of the studied sample knowledge regarding sexual function during pregnancy in both study and control groups before and after intervention $(n=100)$.

\begin{tabular}{|c|c|c|c|c|c|c|c|c|c|c|c|c|}
\hline \multirow{3}{*}{ Knowledge items } & \multicolumn{6}{|c|}{ Before intervention } & \multicolumn{6}{|c|}{ After intervention } \\
\hline & \multicolumn{2}{|c|}{$\begin{array}{l}\text { Control group } \\
\mathbf{n}=\mathbf{5 0}\end{array}$} & \multicolumn{2}{|c|}{$\begin{array}{l}\text { Study group } \\
\mathrm{n}=\mathbf{5 0}\end{array}$} & \multirow{2}{*}{$\mathbf{X} 2$} & \multirow{2}{*}{ p-value } & \multicolumn{2}{|c|}{$\begin{array}{l}\text { Control group } \\
\mathbf{n}=\mathbf{5 0}\end{array}$} & \multicolumn{2}{|c|}{ Study group $\mathbf{n = 5 0}$} & \multirow[t]{2}{*}{$\mathbf{X} 2$} & \multirow[t]{2}{*}{ p-value } \\
\hline & No & $\%$ & No & $\%$ & & & No & $\%$ & No & $\%$ & & \\
\hline \multicolumn{13}{|c|}{ Components of the female reproductive system } \\
\hline $\begin{array}{l}\text { Don't know or wrong } \\
\text { answer }\end{array}$ & 21 & 42.0 & 20 & 40.0 & \multirow{3}{*}{1.17} & \multirow{3}{*}{$>0.05$} & 14 & 28.0 & 0 & .00 & \multirow{3}{*}{47.05} & \multirow{3}{*}{$<0.001 * *$} \\
\hline Inadequate answer & 22 & 44.0 & 26 & 52.0 & & & 18 & 36.0 & 0 & .00 & & \\
\hline Adequate answer & 7 & 14.0 & 4 & 8.0 & & & 18 & 36.0 & 50 & 100.0 & & \\
\hline \multicolumn{13}{|c|}{ Most erotic Place for woman } \\
\hline $\begin{array}{l}\text { Don't know or wrong } \\
\text { answer }\end{array}$ & 24 & 48.0 & 35 & 70.0 & \multirow{3}{*}{5.52} & \multirow{3}{*}{$>0.05$} & 10 & 20.0 & 0 & .00 & \multirow{3}{*}{35.37} & \multirow{3}{*}{$<0.001 * *$} \\
\hline Inadequate answer & 18 & 36.0 & 12 & 24.0 & & & 21 & 42.0 & 3 & 6.0 & & \\
\hline Adequate answer & 8 & 16.0 & 3 & 6.0 & & & 19 & 38.0 & 47 & 94.0 & & \\
\hline \multicolumn{13}{|c|}{ Most erotic Place for man } \\
\hline $\begin{array}{l}\text { Don't know or wrong } \\
\text { answer }\end{array}$ & 30 & 60.0 & 35 & 70.0 & \multirow{3}{*}{2.96} & \multirow{3}{*}{$>0.05$} & 23 & 46.0 & 0 & .00 & & \\
\hline Inadequate answer & 19 & 38.0 & 12 & 24.0 & & & 25 & 50.0 & 4 & 8.0 & 78.45 & $<0.001 * *$ \\
\hline Adequate answer & 1 & 2.0 & 3 & 6.0 & & & 2 & 4.0 & 46 & 92.0 & & \\
\hline The stages of sexual re & ponse & & & & & & & & & & & \\
\hline $\begin{array}{l}\text { Don't know or wrong } \\
\text { answer }\end{array}$ & 0 & .00 & 0 & .00 & & & 0 & .00 & 0 & .00 & & \\
\hline Inadequate answer & 43 & 86.0 & 49 & 98.0 & 4.89 & $>0.05$ & 42 & 84.0 & 3 & 6.0 & 61.45 & $<0.001 * *$ \\
\hline Adequate answer & 7 & 14.0 & 1 & 2.0 & & & 8 & 16.0 & 47 & 94.0 & & \\
\hline Effect of pregnancy on & he st: & f sexua & spon & & & & & & & & & \\
\hline $\begin{array}{l}\text { Don't know or wrong } \\
\text { answer }\end{array}$ & 0 & .00 & 0 & .00 & & & 0 & .00 & 0 & .00 & & \\
\hline Inadequate answer & 16 & 32.0 & 20 & 40.0 & .694 & $>0.05$ & 15 & 30.0 & 49 & 98.0 & 50.17 & $<0.001 * *$ \\
\hline Adequate answer & 34 & 68.0 & 30 & 60.0 & & & 35 & 70.0 & 1 & 2.0 & & \\
\hline Effect of pregnancy on & sexua & & & & & & & & & & & \\
\hline $\begin{array}{l}\text { Don't know or wrong } \\
\text { answer }\end{array}$ & 0 & .00 & 0 & .00 & & & 0 & .00 & 0 & .00 & & \\
\hline Inadequate answer & 14 & 28.0 & 11 & 22.0 & .480 & $>0.05$ & 17 & 34.0 & 47 & 94.0 & 39.06 & $<0.001 * *$ \\
\hline Adequate answer & 36 & 72.0 & 39 & 78.0 & & & 33 & 66.0 & 3 & 6.0 & & \\
\hline How to overcome the 1 & oblen & $\operatorname{sing} d$ & e dur & pregnar & & & & & & & & \\
\hline $\begin{array}{l}\text { Don't know or wrong } \\
\text { answer }\end{array}$ & 0 & .00 & 0 & .00 & & & 0 & .00 & 0 & .00 & & \\
\hline Inadequate answer & 44 & 88.0 & 50 & 100.0 & 6.38 & $<0.05^{*}$ & 45 & 90.0 & 3 & 6.0 & 70.67 & $<0.00 * * 1$ \\
\hline Adequate answer & 6 & 12.0 & & & & & 5 & 10.0 & 47 & 94.0 & & \\
\hline Safety of sexual interc & urse $f$ & fetus d & g pr & ancy: & & & & & & & & \\
\hline $\begin{array}{l}\text { Don't know or wrong } \\
\text { answer }\end{array}$ & 0 & .00 & 0 & .00 & & & 0 & .00 & 0 & .00 & & \\
\hline Inadequate answer & 43 & 86.0 & 47 & 94.0 & 1.77 & $>0.05$ & 43 & 86.0 & 4 & 8.0 & 61.06 & $<0.001 * *$ \\
\hline Adequate answer & 7 & 14.0 & 3 & 6.0 & & & 7 & 14.0 & 46 & 92.0 & & \\
\hline Cases in which sexual & nterce & hould & ivoid & uring $\mathrm{p}$ & ancy: & & & & & & & \\
\hline $\begin{array}{l}\text { Don't know or wrong } \\
\text { answer }\end{array}$ & 24 & 48.0 & 24 & 48.0 & 5.53 & $>0.05$ & 22 & 44.0 & 0 & .00 & 96.07 & $<0.001 * *$ \\
\hline Inadequate answer & 26 & 52.0 & 21 & 42.0 & & & 27 & 54.0 & 0 & .00 & & \\
\hline
\end{tabular}




\begin{tabular}{|c|c|c|c|c|c|c|c|c|c|c|c|c|}
\hline \multirow{3}{*}{ Knowledge items } & \multicolumn{6}{|c|}{ Before intervention } & \multicolumn{6}{|c|}{ After intervention } \\
\hline & \multicolumn{2}{|c|}{$\begin{array}{l}\text { Control group } \\
\mathbf{n}=50\end{array}$} & \multicolumn{2}{|c|}{$\begin{array}{l}\text { Study group } \\
\mathrm{n}=50\end{array}$} & \multirow[t]{2}{*}{$\mathbf{X} 2$} & \multirow[t]{2}{*}{ p-value } & \multicolumn{2}{|c|}{$\begin{array}{l}\text { Control group } \\
\mathbf{n}=50\end{array}$} & \multicolumn{2}{|c|}{ Study group $\mathbf{n}=\mathbf{5 0}$} & \multirow[t]{2}{*}{$\mathbf{X} 2$} & \multirow[t]{2}{*}{ p-value } \\
\hline & No & $\%$ & No & $\%$ & & & No & $\%$ & No & $\%$ & & \\
\hline Adequate answer & 0 & 0.0 & 5 & 10.0 & & & 1 & 2.0 & 50 & 100.0 & & \\
\hline \multicolumn{13}{|c|}{ Positions of sexual intercourse during pregnancy: } \\
\hline $\begin{array}{l}\text { Don't know or wrong } \\
\text { answer }\end{array}$ & 0 & .00 & 0 & .00 & \multirow{3}{*}{.078} & \multirow{3}{*}{$>0.05$} & 0 & .00 & 0 & .00 & \multirow{3}{*}{61.29} & \multirow{3}{*}{$<0.001 * *$} \\
\hline Inadequate answer & 42 & 84.0 & 43 & 86.0 & & & 38 & 76.0 & 0 & .00 & & \\
\hline Adequate answer & 8 & 16.0 & 7 & 14.0 & & & 12 & 24.0 & 50 & 100.0 & & \\
\hline \multicolumn{13}{|c|}{ Most secure positions of sexual intercourse during pregnancy } \\
\hline $\begin{array}{l}\text { Don't know or wrong } \\
\text { answer }\end{array}$ & 38 & 76.0 & 30 & 60.0 & \multirow{3}{*}{4.11} & \multirow{3}{*}{$>0.05$} & 29 & 58.0 & 0 & .00 & \multirow{3}{*}{75.05} & \multirow{3}{*}{$<0.001^{* *}$} \\
\hline Inadequate answer & 10 & 20.0 & 13 & 26.0 & & & 17 & 34.0 & 3 & 6.0 & & \\
\hline Adequate answer & 2 & 4.0 & 7 & 14.0 & & & 4 & 8.0 & 47 & 94.0 & & \\
\hline \multicolumn{13}{|c|}{ Positions of sexual intercourse which should be avoided during pregnancy } \\
\hline $\begin{array}{l}\text { Don't know or wrong } \\
\text { answer }\end{array}$ & 40 & 80.0 & 38 & 76.0 & \multirow{3}{*}{1.71} & \multirow{3}{*}{$>0.05$} & 28 & 56.0 & 0 & .00 & \multirow{4}{*}{65.63} & \multirow{3}{*}{$<0.001 * *$} \\
\hline Inadequate answer & 6 & 12.0 & 10 & 20.0 & & & 15 & 30.0 & 3 & 6.0 & & \\
\hline Adequate answer & 4 & 8.0 & 2 & 4.0 & & & 7 & 14.0 & 47 & 94.0 & & \\
\hline \multicolumn{12}{|l|}{ Total } & \\
\hline Poor & 4 & 8.0 & 5 & 10.0 & \multirow{3}{*}{.706} & \multirow{3}{*}{.401} & 2 & 4.0 & 0 & .00 & \multirow{3}{*}{30.13} & \multirow{3}{*}{$<0.001 * *$} \\
\hline Average & 37 & 74.0 & 39 & 78.0 & & & 34 & 68.0 & 7 & 14.0 & & \\
\hline Good & 9 & 18.0 & 6 & 12.0 & & & 14 & 28.0 & 43 & 86.0 & & \\
\hline
\end{tabular}

*A Statistical significant $\mathrm{p} \leq 0.05$.

**A Highly Statistical significant $\mathrm{p} \leq 0.001$.

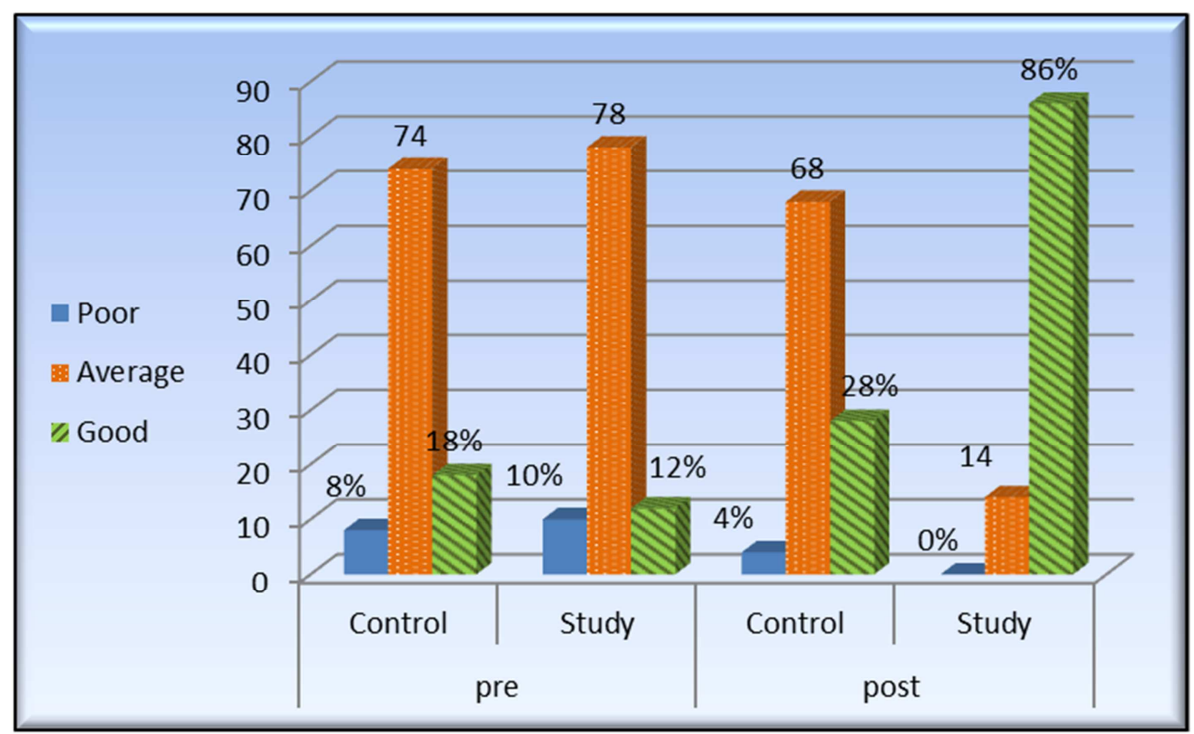

Figure 1. Distribution of the studied sample total knowledge regarding sexual intercourse during pregnancy in both study and control groups before and after intervention $(n=100)$.

Table 5. Mean scores of studied sample regarding their FSFI six domains and total scores in both study and control groups before and three phases after intervention $(n=100)$.

\begin{tabular}{|c|c|c|c|c|c|c|c|}
\hline \multirow{3}{*}{$\begin{array}{l}\text { Domains of } \\
\text { FSFI }\end{array}$} & \multirow{3}{*}{ Groups } & \multirow{2}{*}{$\begin{array}{l}\text { Before intervention } \\
\text { First trimester (10-12 } \\
\text { weeks) }\end{array}$} & \multicolumn{3}{|c|}{ After intervention } & \multirow{3}{*}{ F -test } & \multirow{3}{*}{ p-value } \\
\hline & & & $\begin{array}{l}4 \text { weeks after } \\
\text { intervention }\end{array}$ & $\begin{array}{l}\text { Second trimester } \\
\text { (26-28 weeks) }\end{array}$ & $\begin{array}{l}\text { Third trimester } \\
\text { (34-36 weeks) }\end{array}$ & & \\
\hline & & Mean \pm SD & Mean \pm SD & Mean \pm SD & Mean \pm SD & & \\
\hline \multirow{2}{*}{ Desire } & Control group & $3.96 \pm 1.27$ & $5.70 \pm 1.44$ & $6.20 \pm 1.14$ & $4.32 \pm 1.18$ & \multirow{2}{*}{170.72} & \multirow{2}{*}{$<0.001 * *$} \\
\hline & Study group & $3.82 \pm .71$ & $8.66 \pm .96$ & $9.30 \pm .61$ & $6.66 \pm 1.36$ & & \\
\hline \multirow{2}{*}{ Arousal } & Control group & $4.30 \pm 2.63$ & $13.50 \pm 3.09$ & $10.24 \pm 1.75$ & $6.54 \pm 2.96$ & \multirow{2}{*}{263.59} & \multirow{2}{*}{$<0.001 * *$} \\
\hline & Study group & $6.06 \pm 2.75$ & $17.16 \pm 1.78$ & $18.84 \pm 1.07$ & $14.16 \pm 1.98$ & & \\
\hline
\end{tabular}




\begin{tabular}{|c|c|c|c|c|c|c|c|}
\hline \multirow{3}{*}{$\begin{array}{l}\text { Domains of } \\
\text { FSFI }\end{array}$} & \multirow{3}{*}{ Groups } & \multirow{2}{*}{$\begin{array}{l}\text { Before intervention } \\
\text { First trimester (10-12 } \\
\text { weeks) }\end{array}$} & \multicolumn{3}{|c|}{ After intervention } & \multirow{3}{*}{ F -test } & \multirow{3}{*}{ p-value } \\
\hline & & & $\begin{array}{l}4 \text { weeks after } \\
\text { intervention }\end{array}$ & $\begin{array}{l}\text { Second trimester } \\
\text { (26-28 weeks) }\end{array}$ & $\begin{array}{l}\text { Third trimester } \\
\text { (34-36 weeks) }\end{array}$ & & \\
\hline & & Mean \pm SD & Mean \pm SD & Mean \pm SD & Mean \pm SD & & \\
\hline \multirow{2}{*}{ Lubrication } & Control group & $6.12 \pm 2.68$ & $11.94 \pm 2.96$ & $11.04 \pm 2.19$ & $8.10 \pm 2.82$ & \multirow{2}{*}{169.57} & \multirow{2}{*}{$<0.001 * *$} \\
\hline & Study group & $7.30 \pm 3.05$ & $14.84 \pm 1.63$ & $19.10 \pm 1.18$ & $15.14 \pm 2.25$ & & \\
\hline \multirow{2}{*}{ Orgasm } & Control group & $4.00 \pm 1.80$ & $10.02 \pm 2.36$ & $9.66 \pm 2.54$ & $6.12 \pm 2.97$ & \multirow{2}{*}{107.34} & \multirow{2}{*}{$<0.001 * *$} \\
\hline & Study group & $5.40 \pm 2.42$ & $9.52 \pm 1.37$ & $13.86 \pm 1.70$ & $10.66 \pm 2.05$ & & \\
\hline \multirow{2}{*}{ Satisfaction } & Control group & $5.06 \pm 1.75$ & $5.50 \pm 1.79$ & $5.04 \pm 1.60$ & $6.38 \pm 2.37$ & \multirow{2}{*}{229.83} & \multirow{2}{*}{$<0.001^{* *}$} \\
\hline & Study group & $5.50 \pm 1.78$ & $8.16 \pm 1.18$ & $14.30 \pm 1.05$ & $11.74 \pm 1.02$ & & \\
\hline \multirow{2}{*}{ Pain } & Control group & $5.66 \pm 3.35$ & $7.56 \pm 1.41$ & $7.44 \pm 1.80$ & $5.62 \pm 1.79$ & \multirow{2}{*}{223.94} & \multirow{2}{*}{$<0.001 * *$} \\
\hline & Study group & $4.32 \pm 2.22$ & $14.20 \pm .96$ & $14.52 \pm 1.52$ & $12.30 \pm 1.40$ & & \\
\hline \multirow{2}{*}{ Total } & Control group & $29.10 \pm 8.14$ & $54.22 \pm 5.77$ & $49.62 \pm 3.76$ & $37.08 \pm 7.82$ & \multirow{2}{*}{741.56} & \multirow{2}{*}{$<0.001 * *$} \\
\hline & Study group & $32.40 \pm 4.55$ & $72.54 \pm 3.94$ & $89.92 \pm 3.78$ & $70.66 \pm 5.35$ & & \\
\hline
\end{tabular}

*A Statistical significant $\mathrm{p} \leq 0.05 * *$ A Highly Statistical significant $\mathrm{p} \leq 0.001$.

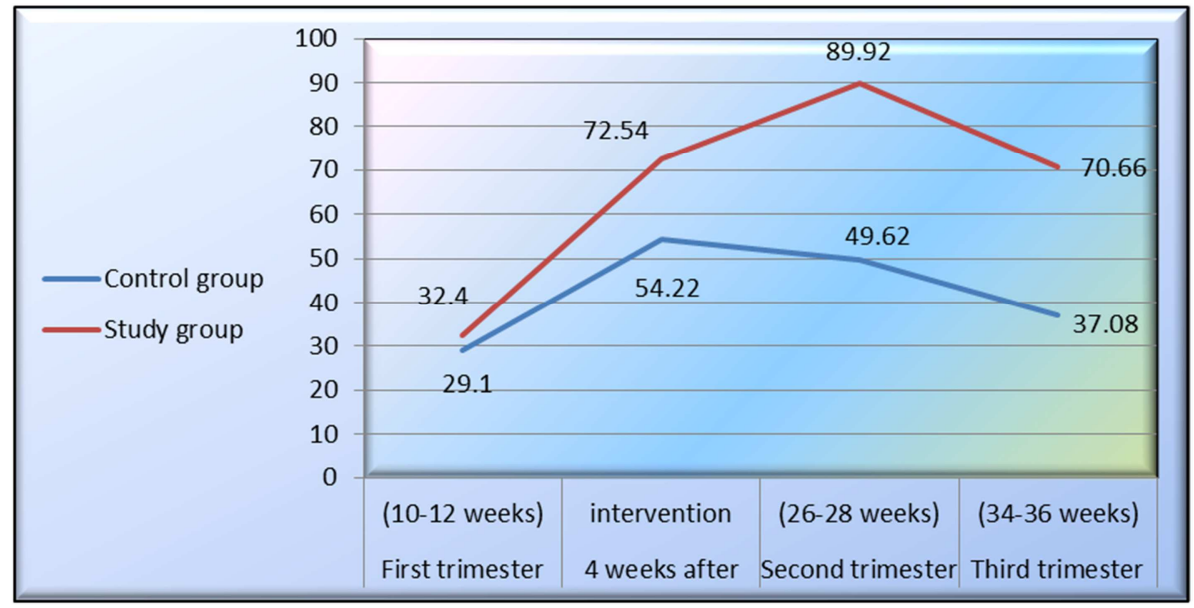

Figure 2. Trend of mean scores of FSFI scores in both study and control groups before and three phases after intervention ( $n=100)$.

Table 6. Correlation coefficient between total scores of FSFI and total knowledge of the studied sample before and after intervention at third trimester $(n=100)$.

\begin{tabular}{|c|c|c|c|c|c|}
\hline \multirow{3}{*}{ Variables } & & \multicolumn{4}{|c|}{ Total Knowledge } \\
\hline & & \multicolumn{2}{|c|}{ Before intervention } & \multicolumn{2}{|c|}{ After intervention } \\
\hline & & $\mathbf{R}$ & $\mathbf{p}$ & $\mathbf{r}$ & $\mathbf{p}$ \\
\hline \multirow{2}{*}{ Total Score of FSFI } & Study group & 0.186 & 0.195 & 0.621 & $0.03 *$ \\
\hline & Control group & 0.233 & 0.104 & 0.145 & 0.314 \\
\hline
\end{tabular}

\section{Discussion}

Pregnancy is one of the most serious periods in women's lives1. Sexuality is an important part of health and wellbeing. According to the World Health Organization, safe sexual experiences cannot be only defined as the absence of sexual dysfunction, but as a state of physical, emotional, mental, and social well- being related to sexuality. Most of sexual problems during pregnancy arise from the lack of knowledge and experience, misconception of sex, or disability of women to express their sexual preferences [7].

In this research the researchers attempted to evaluate effect of the sexual educational package on knowledge and female sexual function for pregnant women. The findings of this research were approved the research hypotheses which are the women who received a sexual education package would expect to improve their knowledge and female sexual function index after implementing sexual educational package than those who don't as indicated by pre and post test scores.

Findings of this research study showed that, there was about two thirds of both study and control groups respectively were in age group less than 25 years with a mean age of $23.80 \pm 3.43$ years and $24.18 \pm 1.63$ years respectively, the mean age at marriage was $21.56 \pm 2.80$ and $22.34 \pm 2.13$ years of both study and control groups respectively. The mean of marriage duration for both study and control groups was $(1.80 \pm 1.10$ and $1.36 \pm .59$ years respectively). As regards the residence, more than half of the study and control group were lived in rural area. Furthermore, educational level of more than one quarter and more than one third of both study and control groups respectively were middle education. Regarding the 
employment, more than two thirds of both study and control groups respectively weren't work. As far as monthly income, about half of both the study and control groups respectively had insufficient income.

These findings are agreement with Abdelhakm, etal. who studied "effect of PLISSIT Model sexual counseling program on sexual quality of life for postpartum women, Egypt " [16], reported that; most of studied women were from 20 to 30 years with the mean age $25.02 \pm 4.47$, It was found that; about half of these women their marriage duration from one to five years with the Mean \pm SD $6.98 \pm 4.43$. Regarding marriage age; more than half of them were from 20 to 30 years with the Mean \pm SD $22.84 \pm 4.67$, more than one-third were had middle education, more than two-thirds of studied women were living in rural areas and the majority of women were housewives. This middle education level and culture of rural areas may be the cause for avoiding discussion about sexual issues.

In the current research more than half of the women in both study and control groups were related to nuclear families. This similar to the findings of Yörük.\& Karaçam, who studied "the effectiveness of the PLISSIT Model in solving postpartum sexual problems experienced by women, Turkey"[17] reported that the majority of subjects were living in nuclear families.

The results of the present study showed that there was no significant difference between both groups regarding their personal characteristics, which mean that the two groups under study are homogenous. These results came in same line was the study conducted by Hassan, et al who studied" Effect of PLISSIT Model Sexual Counseling on Sexual Function among Women with Diabetes, Ain Shams, Egypt" [18] found that no statistical significant difference in the baseline characteristics between the studied groups.

Regarding the husband's educational level and jobs of both study and control groups only one third of them were university education and more than two thirds of both the study and control groups were employee. This finding is similar to Jalambadani etal, who studied "Sex Education of Married Women Based on Theory of Planned Behavior" [19], found that more than half of the education level of husband in sex education and control group has been high school degree and university degree, respectively. The three quarters of research units in both groups was homemaker.

The results of the present research revealed that, one third of the study and control groups were gestational age in twelve weeks. Regarding frequency of sexual intercourse, less than half of study and control groups were 2-4 / month. Furthermore, more than three quarters of bokth study and control groups didn't receiving any information about sexual relations before, this may reflect their need for guidance and consultation regarding sexual health issues. The foregoing findings weren't congruent with Jaimie, eta, who studied "Fear-based reasons for not engaging in sexual activity during pregnancy: associations with sexual and relationship well-being" on line survey [20], found that nearly two third of recruited women have sexual relation two times per/week.
Researchers revealed that greater fear-based reasons for not having sex were associated with greater sexual distress but were unrelated to sexual functioning, sexual satisfaction and relationship satisfaction.

Also, the majority of both study and control groups respectively didn't suffer from any sexual problems before pregnancy. But, the majority of both study and control groups complained from presence of sexual problems during the current pregnancy. These results is nearly similar to Vannier, etal who conducted study in Canada under a title " Sexual Distress and Sexual Problems during Pregnancy: Associations with Sexual and Relationship Satisfaction" [21] Illustrated that more than two third of women with sexual distress and women in control group had no sexual problem before pregnancy. However sexual distress is common during pregnancy, associated with lower sexual and relationship satisfaction. This may be explained from researchers view point that pregnancy is a great stressor that affected women sexual life.

The current research showed that, there was no statistically difference between both groups related to obstetric and sexual history, which mean that, the two groups under study are homogenous. These results reflected the importance of manipulating women sexual health and sexual problems as it considered a public health problem which affects most women during pregnancy and may be continued to postnatal period.

The results revealed highly statistically significant difference was found in relation to effect of the implementation of sexual education package on total knowledge score regarding sexual relations or health during pregnancy in pretest and posttest. These findings matched with Ali et al, who studied "the effect of group sexual counseling on the sexual response of pregnant women"[22], showed that sex counseling of sexual function for women in the intervention group was significantly increased in terms of aspects such as sexual desire, intercourse frequency, satisfaction, arousal, orgasm, and sexual quality at post-test from the perspective of women and their partners $(P<0.01)$. Additionally who concluded that positive effect of group sexual counseling on improving the sexual response and sexual activities of women in pregnancy and also recommended educational intervention should be integrated into prenatal consultations and care. This result emphasized the importance of antenatal sexual educational sessions for satisfying, improving the sexual needs of women, reducing stress, and also increasing support by helping to improve the quality of life and the dimensions of marital relationships of pregnant women during this critical period of their lives.

In addition Salimi \& Fatehizadeh, who studied "the Effect of Sex Education on Sexual Knowledge, Self-expression and Intimacy in Married Women" [23], revealed that sexual education by the behavioral cognitive method increases awareness, self-expression and sexual intimacy in women. This finding explained that the educational methods about sexual education has been effective in increasing and correcting the insufficient misconceptions regarding the 
sexual relation in pregnancy

The results of the present research study revealed that a highly significant difference between study and control groups regarding mean FSFI six domains and total scores during the different study phases after implementing sexual education Package. These findings are matched with Afshar et al, who studied "the Effect of Sex Education on the Sexual Function of Women in the First Half of Pregnancy" [24], found that sexual education had increased total score of sexual function and its six aspects, including sexual desire, sexual arousal, orgasm, satisfaction, sexual pain and vaginal lubrication of pregnant women in the intervention group. This may reflect that sexual education and consultation during pregnancy has a positive and significant impact in increasing FSF.

These findings are in contrast with Mirmohammad et al, who studied "Effectiveness of a sex Education Program on Sexual Function in Postmenopausal Women with Sexual dysfunction" [25], found that the four sessions of the weekly Training Program, on sexual issues, increased meaningfully sexual function score and all dimensions except orgasm. This may be due to obedience, shyness, sensitivity to other's needs, insufficient affection, and inadequate making mutual understanding. These reflected that sexual-counseling strategies can be used by the health care providers to assist them in gradual discussing the topic of sexual health and providing supportive counseling and intervention.

Additionally, the findings of current research goes in same line with Nasim et al, who studied "the Effect of Educational Package on Sexual Function in Cold Temperament Women of Reproductive Age" [26], showed that the sexual education package improved the sexual function of cold temperament women, also added that the educational package program is an easy, available, non-pharmacological and economic program that can be trained by health center staff to cold temperament reproductive age women and included in routine care to be one of these ways to promote sexual function.

Furthermore, these results is in accordance with Heidari et al, who studied "Effect of an Educational Intervention on the Sexual Life during Pregnancy of Iranian Couples"[27], indicated that there were improvements in the sexual function of women for the study group after sexual education, this probably is attributed to the fact that sexual counseling is one of the most important issues which had positive effect on improving the sexual response and sexual activities of women during pregnancy, this may lead to increase satisfaction and improving the sexual needs of women, reducing pain, and also helping to improve the quality of life during this critical period of their lives.

Another study conducted by Jalambadani et al, who studied "Sex Education of Married Women Based on Theory of Planned Behavior" [19], showed that, the score of sexual function after intervention in sex education group had a meaningful difference compared to that of score before intervention in the same group, which this score has not been meaningful in control group, this probably is attributed to the fact that, the sexual knowledge and awareness of women is followed by pleasure and improvement of marital and emotional relationship between them. If all pregnant women in the study group have a better understanding about this important dimension of relationship, they will be able to change their communication methods and to improve them and to take an appropriate solution against the incidence of marital conflicts and problems. This may be due to that sexual education plays an important role for improving sexual function in pregnancy. In addition, sex education is effective in prevention of sexual disorders in pregnancy.

These findings incongruent with Wannakosit \& Phupong who studied "Sexual Behavior in Pregnancy: Comparing between Sexual Education Group and Non-Sexual Education Group" [28], showed that no statistically significant differences between the two intervention groups and the control group after education. This disagreement of current study with the results of this study could be due to different demographic characteristics of the studied population, educational tools and methods used for the education.

The results of present research demonstrate that the highest mean scores of FSFI was observed in the time of (26-28 weeks- second trimester) after intervention for study group, while the minimum mean scores of FSFI was related to the time of (10-12 weeks-first trimester) before intervention. Meanwhile, for control group, the highest mean scores of FSFI was observed in the time of 4 weeks after intervention. While the minimum mean scores of FSFI was related to the time of (10-12 weeks-first trimester) before intervention. This result agreed with Heidari et al, who studied " Effect of Sexual Education on Sexual Function of Iranian Couples during Pregnancy: A Quasi Experimental Study"[27], illustrated that there were significant differences between groups in mean FSFI total scores during the study period, where, the highest difference could be observed in the time period of 4 weeks after intervention, while the minimum mean difference was related to the third trimester.

The data from our research indicated that, a highly significant correlation was discovered between total scores of FSFI and total knowledge in study group after implementing sexual education package. These results came in agreement with Saboula, \& Shahin who studied "Effectiveness of Application of PLISSIT Counseling Model on Sexuality for Breast Cancer's Women Undergoing Treatment, Egypt" [29], showed that, a highly significant correlation between the sexual health enhancement program and improving sexual function.

Also this result agreed with Mojdeh et al, who studied " Addressing the Sexual Function of Women during First Six Month after Delivery: A quasi-Experimental Study, [30] illustrated that before intervention, the mean score of sexual function between the two groups was not significantly different. Also, four weeks after consultation, there found highly statistical significant difference in the mean score of sexual function between two groups. These differences were highly statistically significant.

Additionally, the result of present research was matched 
with Sung, et al, who studied "Sexual Health Care for Women with Dyspareunia in Taiwan "[31], reported that sexualcounseling strategies can be used by the health care providers to assist them in gradual discussing the topic of sexual health and providing supportive counseling and intervention. These results could be explained by a post-intervention improvement after sexual health enhancement program is effective for improving all the dimensions of sexual functioning.

Furthermore the results of the research are consistent with the study Omer \& Haidar who studied "Applicability of the Theory of Planned Behavior in Predicting Intended Use of Voluntary HIV Counseling and Testing services among Teachers of Hariri Region, Ethiopia" [32] concluded that all women acquire enough knowledge along with positive attitude toward sexual function, feel that environmental factors (facilities and barriers) are in their own willpower and they will have the better sexual function

\section{Conclusion}

Based on the findings of the current research; the research study concluded that research hypotheses was supported and the sexual educational package had a significant effect on improvement of primigravida pregnant women sexual function and knowledge after implementing sexual educational package. There was a highly significant difference between study and control groups regarding mean FSFI six domains and total scores during the different study phases after implementing sexual educational package. There was a highly significant correlation was discovered between total scores of FSFI and total knowledge in study group after implementing sexual education package.

\section{Recommendations}

Educational sexual package intervention must be integrated into prenatal consultations and care. This may lead to satisfying and improving the sexual needs of pregnant women during this critical period of their lives.

Establish strategies to facilitate the women's understanding to discuss sexual disorders freely through apply this study on a large sample in the obstetrics and gynecological outpatient clinics.

\section{Future Researches}

Specialized nurses in obstetrics and gynecological departments allover hospitals should provide sexual education and counseling sessions for pregnant women to promote sexual health.

Evidence based researches on maternity nurses about how to cope with pregnant women regarding sexual issues according to sexual counseling program model

\section{Acknowledgements}

The authors announced their gratitude and appreciation to all pregnant women for their participation and cooperation in the research study, as well as the health care workers in obstetrics and gynecological departments at Benha University Hospitals.

\section{References}

[1] Tiznobek A, Mirmolaei ST, Momenimovahed Z, Kazemnejad A, Taheri S. (2017): Effect of counseling on sexual function and behavior in postmenopausal women and their spouses: a randomized, controlled trial (RCT) study, Menopause Rev; 16 (3): 99-103.

[2] Pirdadeh BS, Behboodi MZ, Salsali M, Alavi MH, Birjandi M, et al. (2017): Prevalence of Fear of Childbirth and Its Associated Factors in Prim gravid Women: A Cross- Sectional Study. Shiraz E-Med J; 18 (11): e61896.

[3] Bostani KZ and Ghanbary K A. (2015): Perception and experience of married women of reproductive age about the importance of sexual health education: A content analysis study. Iranian Journal of Obstetrics, Gynecology and Infertility; 18 (172): 7-17.

[4] Yeniel AO and Petri E. (2014): Pregnancy, childbirth, and sexual function: perceptions and facts. Int Urogynecol J; 25 (1): 5-14.

[5] Navidian A, Rigi SN, Soltani P. (2016): Effects of group sexual counseling on the traditional perceptions and attitudes of Iranian pregnant women. Int J Womens Health; 8: 203-11.

[6] Sossah L. (2014): Sexual behavior during pregnancy: a descriptive correlational study among pregnant women. Eur J Med Res; 2 (1): 16-27.

[7] Gałązka I, Drosdzo Cop A, Naworska B, Czajkowska M, Skrzypulec Plinta V. (2015): Changes in the sexual function during pregnancy. J Sex Med; 12 (2): 445-54.

[8] Nakić Radoš S, Soljačić Vraneš H, Šunjić M. (2015): Sexuality during pregnancy: what is important for sexual satisfaction in expectant fathers? J Sex Marital There; 41 (3): 282-93.

[9] Bahadoran P, Mahdiabadzade MM, Nasiri H, Dehaghi AG. (2018): The effect of face to face or group education during pregnancy on sexual function of couples in Isfahan, Iranian Journal of Nursing and Midwifery 20 (5): 582-587.

[10] De Pierrepont C and Polomeno V. (2014): Role of the perinatal sexologist in the interdisciplinary perinatal health care team in Canada. Gynecol. Obstet. Fertile.; 42 (7): 507-14.

[11] Cunningham F, Leveno K, Bloom S, Hauth J, Rouse D, Spong C. (2016): Williams Obstetrics. 23rd ed. McGraw-Hill Education.

[12] Saduck BJ, Sadock VA, Ruiz P. Kaplan (2012): Sadock's comprehensive textbook of psychiatry. 11th ed. Philadelphia: Lippincott Williams and Wilkins.

[13] Vakilian K, Kheiri M, Majidi A. (2018): Effect of CognitiveBehavioral Sexual Counseling on Female Sexual Function during Pregnancy: An Interventional Study, International Journal of Women's Health and Reproduction Sciences. 6 (3), 369-373.

[14] Benha University Hospital statistical Census Center (2018): Annual obstetric department census. 
[15] Wiegel M, et al. (2005): The Female Sexual Function Index (FSFI): A Multidimensional Self-Report Instrument for the Assessment of Female Sexual Function. Journal of Sex and Marital Therapy; 31 (1): 1-20.

[16] Abdelhakm E., M, Said A., R, Sobhy D., M (2018) Effect of PLISSIT Model Sexual Counseling Program on Sexual Quality of Life for Postpartum Women American Journal of $\begin{array}{llll}\text { Nursing } & \text { Science; } & 7 & \text { (2): }\end{array}$ http://www.sciencepublishinggroup.com/j/ajns.

[17] Yörük F.\& Karaçam Z. (2016): The Effectiveness of the PLISSIT Model in Solving Postpartum Sexual Problems Experienced by Women, Athens Journal of Health.; 3 (3): 235237.

[18] Hassan, NFK, Metwally, NSM, Salama, AS., (2018): Effect of PLISSIT Model Sexual Counseling on Sexual Function among Women with Diabetes, IOSR Journal of Nursing and Health Science, 7 (4): 34-42.

[19] Jalambadani Z, Garmarodi G, Tavousi M. (2017): Sex education of married women based on theory of planned behavior. CHRISMED J Health Res; 4: 180-5. Journal of Health and Research | Published by Wolters Kluwer Medknow.

[20] Jaimie KB, Sarah AV, and Natalie OR. (2018): Fear-based reasons for not engaging in sexual activity during pregnancy: associations with sexual and relationship well-being, Journal of Psychosomatic Obstetrics \& Gynecology, 39 (2): 138-145.

[21] Vannier T, SarahA, and Rosen B. (2017): Sexual Distress and Sexual Problems During postpartum: Associations with Sexual and Relationship Satisfaction, The Journal of Sexual Medicine, 14 (3): 387-395.

[22] Ali N, Asadollah K, Mahmood I, Batol T, Parvin S. (2017): The effect of group sexual counseling on the sexual response of pregnant women 10.15296/ijwhr. 11. International Journal of Women's Health and Reproduction Sciences Vol. 5, No. 1, January, 60-65 http://www.ijwhr.net.

[23] Salimi M, Fatehizadeh M. (2012): The effect of sex education on sexual knowledge, self-expression and intimacy in married women of Mobarakeh city. Psychological New Researches Journal; 7 (12): 111-128.

[24] Afshar M, M, Alizadeh-C S, Merghti- KE, Yavarikia P. (2012): The effect of sex education on the sexual function of women in the first half of pregnancy a randomized controlled trial. J Caring Sci.; 1 (4): 173-81.

[25] Mirmohammad A, Pakghohar M, Mahmoodi M. (2015): Effectiveness of a sex education program on sexual function in post-menopausal women with sexual dysfunction: A randomized trial [InPersian]. Payesh; 15 (2): 181-92.

[26] Nasim B, Akbarzadeh, M T, Morteza M, Seyed R M. (2018): The effect of educational package on sexual function in cold temperament women of reproductive age Downloaded free from http://www.jehp.net on Wednesday, November 14, IP: 156.210.254.213.

[27] Heidari M, Amin S. F, Zayeri F, Azin SA, Merghati-K E. (2017): Sexual life during pregnancy: effect of an educational intervention on the sexuality of Iranian couples: a quasiexperimental study Sex Marital Ther.: 1-11.

[28] Wannakosit S, Phupong V. (2010): Sexual behavior in pregnancy: comparing between sexual education group and nonsexual education group. J Sex Med.; 7 (10): 3434-8.

[29] Saboula, N, and Shahin M. (2015): Effectiveness of Application of PLISSIT Counseling Model on Sexuality for Breast Cancer's Women Undergoing Treatment, Egypt, American Journal of Nursing Science; 4 (4): Pp. 218-230.

[30] Mojdeh B., Sanaz S, and Hadis S. (2017): Addressing the Sexual Function of Women During First Six Month After Delivery: Aquasi-Experimental Study, Original Article, 10 (6): 1763-1769.

[31] Sung, S, Jeng Ch, and Lin Y. (2011): Sexual health care for women with dyspareunia, Taiwan, Taiwanese Journal of Obstetrics \& Gynecology; 50: Pp. 268-274.

[32] Omer S, Haidar J. (2010): Applicability of the theory of planned behavior in predicting intended use of Voluntary HIV Counseling and Testing services among teachers of Harari Region, Ethiopia. Ethiop J Health Dev.; 24: 96-102. 